\title{
Yoğun Bakım Ünitesinde Gelişen Klebsiella pneumoniae Enfeksiyonları: Karbapenem Direnci ve Hasta Mortalitesi ile Illgili Risk Faktörleri
}

\author{
Klebsiella pneumoniae Infections in the Intensive Care Unit: \\ Risk Factors Related to Carbapenem Resistance and Patient \\ Mortality
}

\author{
Seyit Ali BÜYÜKTUNA (ID), Mürşit $\operatorname{HASBEK}^{2}$ (ID), Cem ÇELIK²(ID), \\ Meltem ÜNLÜSAVURAN ${ }^{3}$ (ID), Onur AVCI${ }^{4}(I D)$, Sevgi BALTACl ${ }^{1}$ (ID), \\ Kübra FIRTINA TOPCU²(ID), Nazif ELALDI ${ }^{1}$ (ID) \\ ${ }^{1}$ Cumhuriyet Üniversitesi Tıp Fakültesi, Enfeksiyon Hastalıkları ve Klinik Mikrobiyoloji Anabilim Dalı, Sivas. \\ ${ }^{1}$ Cumhuriyet University Faculty of Medicine, Department of Infectious Diseases and Clinical Microbiology, Sivas, Turkey. \\ ${ }^{2}$ Cumhuriyet Üniversitesi Tıp Fakültesi, Tıbbi Mikrobiyoloji Anabilim Dalı, Sivas. \\ ${ }^{2}$ Cumhuriyet University Faculty of Medicine, Department of Medical Microbiology, Sivas, Turkey. \\ ${ }^{3}$ Erciyes Üniversitesi Tıp Fakültesi, Biyoistatistik Anabilim Dalı, Kayseri. \\ ${ }^{3}$ Erciyes University Faculty of Medicine, Department of Biostatistics, Kayseri, Turkey. \\ ${ }^{4}$ Cumhuriyet Üniversitesi Tıp Fakültesi, Anesteziyoloji ve Reanimasyon Anabilim Dalı, Sivas. \\ ${ }^{4}$ Cumhuriyet University Faculty of Medicine, Department of Anesthesiology and Reanimation, Sivas, Turkey.
}

Makale Atıfı: Büyüktuna SA, Hasbek M, Çelik C, Ünlüsavuran M, Avcı O, Baltacı S ve ark. Yoğun bakım ünitesinde gelişen Klebsiella pneumoniae enfeksiyonları: karbapenem direnci ve hasta mortalitesi ile ilgili risk faktörleri. Mikrobiyol Bul 2020;54(3):378-391.

\section{ÖZ}

Klebsiella pneumoniae, yoğun bakım ünitelerinde sepsis, üriner sistem enfeksiyonu, kateter ilişkili enfeksiyonlar, pnömoni ve cerrahi alan enfeksiyonları gibi komplike ve tedavisi zor nozokomiyal enfeksiyonlardan sorumludur. K.pneumoniae ile ortaya çıkan enfeksiyonlarda yaşanan en büyük problem çoklu antibiyotik direnci nedeniyle tedavi seçeneklerinin kısıtlı olması ve bunun sonucunda morbidite ve mortalitenin artmasıdır. Karbapenemlerin yaygın ve uygunsuz kullanımı sonrası bu grup antibiyotiklere karşı kazanılmış direnç özellikle yoğun bakım ünitelerinde kontrolü zor salgınlara neden olabilmektedir. Karbapeneme dirençli K.pneumoniae (KDKP) türlerinin neden olduğu salgınlar ve sporadik olgular son yıllarda tüm dünyada giderek artan sıklıkta bildirilmeye başlanmıştır. Bu çalışmada, bir üniversite hastanesi anestezi yoğun bakım ünitesinde gelişen K.pneumoniae ile ilişkili enfeksiyonlarda, karbapenem direnci ve hasta mortalitesi ile ilişkili risk faktörlerinin belirlenmesi amaçlanmıştır. Bu çalışma, 01.01.2016-31.12.2018 tarihleri arasında geriye dönük olarak, hasta ve laboratuvara dayalı sürveyans ile elde edilen veriler kullanılarak gerçekleştirilmiştir. Yoğun bakım ünitesine yatışından 48 saat sonra alınan kan, idrar, apse ve trakeal aspirat örneklerinde K.pneumoniae üremesi olan, enfeksiyon odağı ile ilişkili etkene yönelik antibakteriyel tedavi başlanan erişkin hastalar ( $\geq 18$ yaş) araştırmaya dahil edilmiştir. Kan örneği dışında kalan klinik örnekler, \%5 koyun kanlı agar ve "eosin-methylene-blue (EMB)" agar besiyerlerine ekilmiştir. Kan örnekleri kan kültür şişelerine ekilerek otomatize sistemde inkübe edilmiştir. Beş gün içerisinde üreme sinyali veren örnekler için Gram boyama yapılarak ön tanımlama yapılmış, daha sonra \%5 koyun kanlı agar ve EMB 
agar besiyerlerine pasaj yapılarak $35.5-37^{\circ} \mathrm{C}^{\prime}$ de $18-24$ saat inkübe edilmiştir. İolatların tanımlanması "matrix-assisted laser desorption/Ionization time-of-mass spectrometry (MALDI-TOF MS)" temelli Bruker IVD MALDI Biotyper 2.3 (Bruker Daltonik GmbH, Bremen, Almanya) cihazı kullanılarak gerçekleştirilmiştir. Çalışmamızda yer alan K.pneumoniae izolatları 2.0 ve üzeri güvenilirlik skorları elde edilmesiyle tanımlanmıştır. K.pneumoniae izolatlarında antibiyotik duyarlıık testleri Phoenix 100 (BD, New Jersey, ABD) otomatize sistemiyle gerçekleştirilmiş ve sonuçlar "European Committee on Antimicrobial Susceptibility Testing (EUCAST)" önerilerine göre yapılmıştır. KDKP izolatlarında karbapenemaz varlığını göstermek için kombine disk difüzyon testi ve polimeraz zincir reaksiyonu temelli testler kullanılmışır. K.pneumoniae enfeksiyonu gelişen toplam 88 hasta çalışmaya dahil edilmiştir. Hastaların yaş ortalaması $74 \pm 15$ (yaş aralığı: 21-93) yıl ve \%60.2'si kadınlardan oluşmuştur. KDKP 32 (\%36.4) hastada, karbapeneme duyarlı/ hassas K.pneumoniae (KHKP) 56 hastada saptanmıştır. KDKP saptanan olgularda kombine disk difüzyon yöntemi ile yapılan tarama testinde \%68.8 oranında OXA-48 varlığı saptanmıştır. K.pneumoniae enfeksiyonu gelişen hastalar arasından KDKP gelişimi açısından son 3 aylık dönem içerisinde kolistin [Odds oranı $(O R)=19.108 ; \% 95$ güven aralığ $(G A)=2.027-180.133 ; p=0.010]$ ve aminoglikozit $(O R=12.189 ; \% 95$ $\mathrm{GA}=1.256-118.334 ; \mathrm{p}=0.031)$ kullanımı bağımsız risk faktörleri olarak bulunmuştur. Çalışma döneminde 28 günlük mortalite oranları KDKP grubunda (23/32) \%71.9, KHKP grubunda (21/56) \%37.5 olarak bulunmuştur. Yirmi sekiz günlük mortalite gelişimi açısından KDKP varlığı $(O R=5.146 ; \% 95 \mathrm{GA}=1.839$ 14.398; $p=0.002$ ) bağımsız risk faktörü olarak saptanmıştır. Bu çalışmada elde edilen veriler KDKP'deki artışı önlenmesi için etkili ve sürekli sürveyans çalışmalarını yürütmek ve akılcı antibiyotik programlarını uygulamak adına yol gösterici olacaktır.

\section{Anahtar kelimeler: Yoğun bakım ünitesi; mortalite; risk faktörü; karbapenem direnci; Klebsiella pneumo-} niae.

\section{ABSTRACT}

Klebsiella pneumoniae is the cause of complicated and difficult-to-treat nosocomial infections such as sepsis, urinary tract infection, catheter related infections, pneumonia and surgical site infections in intensive care units. The biggest problem in infections with K.pneumoniae is that treatment options are limited due to multiple antibiotic resistance and consequently the increased morbidity and mortality. The widespread and improper use of carbapenems can lead to epidemics that are difficult to control, especially in intensive care units because of the acquired resistance to this group of antibiotics. Outbreaks and sporadic cases caused by carbapenem resistant K.pneumoniae (CRKP) species have been reported all over the world in recent years with increased frequency. The aim of this study was to determine the risk factors related to carbepenem resistance and mortality caused by K.pneumoniae infections in a university hospital anesthesia intensive care unit. The study was conducted between January $1^{\text {st }}, 2016$, and December 31 1 st 2018. Retrospective data were obtained from the patient and laboratory-based surveillance records. Adult patients ( $\geq 18$ years) with K.pneumoniae growth in the blood, urine, abscess and tracheal aspirate samples collected 48 hours after admission to the intensive care unit were considered as the relevant infection locus-related agent and treated with antibacterial therapy. Clinical samples collected from patients were inoculated onto $5 \%$ sheep blood and eosin-methylene-blue (EMB) agar except the blood samples. Blood samples were cultured in blood culture bottles and incubated in an automated system. Gram staining was performed for the samples showing growth signal within five days and then inoculated onto 5\% sheep blood and EMB agar media and were incubated for 18-24 hours at $35.5-37^{\circ} \mathrm{C}$. Identification of the isolates was performed using Bruker IVD MALDI Biotyper 2.3 (Bruker Daltonik $\mathrm{GmbH}$, Bremen, Almanya) based on "matrix-assisted laser desorption/ionization time-of-mass spectrometry (MALDI-TOF MS)". K.pneumoniae isolates were identified by obtaining reliability scores of 2.0 and above in the study. Antibiotic susceptibility tests were performed with Phoenix 100 (BD, New Jersey, ABD) automated system. Interpretations were made according to the European Committee on Antimicrobial Susceptibility Testing (EUCAST) guidelines. Combination disk diffusion test and polymerase chain reaction based tests were used to show the presence of carbapenemase in CRKP isolates. A total of 88 patients with K.pneumoniae infection were included in the study. The mean age of the patients was $74 \pm 15$ (range $=21-93$ ) years and $60.2 \%$ were female. CRKP was detected in 32 patients $(36.4 \%)$ and carbapenem-sensitive K.pneumoniae (CSKP) was detected in 56 patients. The presence of OXA-48 was found to be $68.8 \%$ in the carbapenem screening test performed by combination disc method in patients 
with CRKP. Multivariate logistic regression analysis showed that previous use of colistin [Odds ratio $(\mathrm{OR})=$ 19.108; 95\% confidence interval $(\mathrm{Cl})=2.027-180.133 ; \mathrm{p}=0.010]$ and aminoglycoside $(\mathrm{OR}=12.189$; $95 \% \mathrm{Cl}=1.256-118.334 ; \mathrm{p}=0.031$ ) was an independent risk factor in terms of CRCP among the patients with K.pneumoniae infection. The 28-day mortality rates were $71.9 \%$ in the CRKP group (23/32) and $37.5 \%$ in the CSKP group (21/56). Presence of CRKP in terms of 28 -day mortality $(\mathrm{OR}=5.146 ; 95 \% \mathrm{Cl}=$ 1.839-14.398; $p=0.002$ ) was an independent risk factor. The data obtained in this study will guide for conducting effective and continuous surveillance studies and implementing rational antibiotic programs to prevent the increase in CRKP.

Keywords: Intensive care unit; mortality; risk factor; carbapenem resistance; Klebsiella pneumoniae

\section{Giriş}

Yoğun bakım üniteleri (YBÜ)'nde en sık izole edilen etkenlerden biri olan Klebsiella pneumoniae, insanlarda gastrointestinal sistemde saprofit olarak bulunan Enterobacterales ailesinin bir üyesidir. Bu bakteri yenidoğanlar, yaşlılar, kronik solunum yolu hastalığı olanlar ve bağışıklığı baskılanmış bireylerde sepsis, üriner sistem enfeksiyonu, kateter ilişkili enfeksiyonlar, pnömoni ve cerrahi alan enfeksiyonları gibi komplike ve tedavisi zor toplum kökenli ve nozokomiyal enfeksiyonlardan sorumludur. K.pneumoniae ile ortaya çıkan nozokomiyal enfeksiyonlarda yaşanan en büyük problem çoklu antibiyotik direnci nedeniyle tedavi seçeneklerinin kısıtlı olması ve bunun sonucunda morbidite ve mortalitenin artmasıdır $^{1-4}$.

Klebsiella türlerinde direncin en önemli mekanizması genişlemiş spektrumlu beta-laktamaz (GSBL) yapımıdır ${ }^{5}$. Karbapenemler özellikle GSBL üreten gram-negatif etkenlerin oluşturduğu enfeksiyonlarda ilk basamak tedavi seçeneğidir. Karbapenemlerin yaygın ve uygunsuz kullanımı sonrası bu grup antibiyotiklere karşı kazanılmış direnç özellikle YBÜ'lerde kontrolü zor salgınlara neden olabilmektedir ${ }^{1,6}$. Karbapeneme dirençli K.pneumoniae (KDKP) türlerinin neden olduğu salgınlar ve sporadik olgular son yıllarda dünyada ve ülkemizde giderek artan sıklıkta bildirilmeye başlanmıştır ${ }^{7,8}$.

Bu çalışmada, bir üniversite hastanesi anestezi YBÜ'de K.pneumoniae'ya bağlı gelişen enfeksiyonlarda, karbapenem direnci ve hasta mortalitesi ile ilişkili risk faktörlerinin belirlenmesi amaçlanmıştır.

\section{GEREÇ ve YÖNTEM}

Bu çalışma, Cumhuriyet Üniversitesi Girişimsel Olmayan Klinik Araştırmalar Etik Kurulu onayı ile gerçekleştirildi (Tarih: 11.09.2019 ve Karar no: 2019-09/12).

Bu çalışma, 01.01.2016-31.12.2018 tarihleri arasında geriye dönük olarak, hasta ve laboratuvar sonuçlarına dayalı sürveyans ile elde edilen veriler kullanılarak gerçekleştirildi. Nozokomiyal enfeksiyonların tanımlanması Amerika Birleşik Devletleri (ABD) Hastalık Kontrol ve Önleme Merkezi [Centers for Diseases Control and Prevention (CDC)] tarafından belirlenen sürveyans tanı kriterlerine göre yapıldı9. YBÜ’ye yatışından 48 saat sonra alınan kan, idrar, apse ve trakeal aspirat örneklerinde K.pneumoniae üremesi olan, enfeksiyon odağı ile ilişkili olarak etken kabul edilen ve antibakteriyel tedavi verilen erişkin 
hastalar ( $\geq 18$ yaş) araştırmaya dahil edildi. Klinik örneklerinde K.pneumoniae üremesi olan ancak kolonizasyon olarak kabul edilen ve antibakteriyel tedavi verilmeyen olgular çalışma kapsamına alınmadı. Her hastanın ilk pozitif örneği çalışmada analiz edildi.

Kan örneği dışında kalan klinik örnekler, \%5 koyun kanlı agar ve "eosin-methyleneblue (EMB)" agar besiyerlerine ekildi. Kan örnekleri kan kültür şişelerine (Bactec FXBecton Dickinson ${ }^{\circledR}$, Maryland, ABD) ekilerek otomatize sistemde (BACTEC 9120, BD Diagnostic Instrument Systems, Sparks, MD, ABD) inkübe edildi. Beş gün içerisinde üreme sinyali veren örnekler, Gram boyama ile ön tanımlama yapılıp \%5 koyun kanlı ve EMB agar besiyerlerine pasaj yapılarak $35.5-37^{\circ} \mathrm{C}^{\prime}$ de $18-24$ saat inkübe edildi. İzolatların tanımlanması "matrix-assisted laser desorption/ionization time-of-mass spectrometry (MALDI-TOF MS)" temelli Bruker IVD MALDI Biotyper 2.3 (Bruker Daltonik GmbH, Bremen, Almanya) cihazı kullanılarak, üretici firmanın önerdiği çalışma protokolü dahilinde gerçekleştirildi. Çalışmada K.pneumoniae izolatları, 2.0 ve üzeri güvenilirlik skorları belirlenerek tanımlandı. Elde edilen K.pneumoniae izolatlarında antibiyotik duyarlılık testleri Phoenix 100 (Becton Dickinson, Sparks, MD, ABD) otomatize sistemiyle gerçekleştirildi. Sonuçlar, "European Committee on Antimicrobial Susceptibility Testing (EUCAST)" önerilerine göre değerlendirildi ${ }^{10}$. Elde edilen izolatlarda ertapenem için minimum inhibitör konsantrasyonu (MiK) değeri > $1 \mu \mathrm{g} / \mathrm{ml}$, imipenem ve/veya meropenem için MiK değerleri $>8 \mu \mathrm{g} / \mathrm{ml}$ olan izolatlar karbapeneme dirençli olarak kabul edildi. KDKP izolatlarında karbapenemaz varlığını göstermek için kombine disk difüzyon testi Mastdiscs Combi CARBA PLUS (Mast Group, Merseyside, Birleşik Krallık) ve polimeraz zincir reaksiyonu (PCR) temelli BD MAX Check-Points CPO (Check-Points Health BV, Wageningen, Hollanda) test kitleri kullanıldı. OXA-48 varlığı 22 hastadan ikisinde BD MAX Check-points CPO (Check-Points Health BV, Wageningen, Hollanda) yöntemiyle, diğer 20 hastada ise Mastdiscs Combi CARBA PLUS (Mast Group, Merseyside, Birleşik Kralık) yöntemiyle saptandı. Metallo-beta-laktamaz (MBL) ve K.pneumoniae karbapenemaz (KPC) varlığı ise Mastdiscs Combi CARBA PLUS (Mast Group, Merseyside, Birleşik Krallık) yöntemiyle belirlendi.

\section{İstatistiksel Analiz}

Sürekli değişkenler ortalama \pm standart sapma şeklinde, nominal değişkenler ise olgu sayısı ve yüzde (\%) olarak gösterildi. Kategorik değişkenler arasındaki ilişkilerin değerlendirilmesinde ki-kare analizi, mortalite ve KDKP değişkenlerine etki eden risk faktörlerinin belirlenmesinde tek değişkenli ve çok değişkenli lojistik regresyon analizleri kullanıldı. Tek değişkenli lojistik regresyon analizi sonucunda istatistiksel olarak anlamlı bulunan değişkenler $(p<0.10)$ çoklu lojistik regresyon analizine alınarak Odds oranı (OR) ve \%95 güven aralığı (\%95 GA) belirlendi. İstatistiksel anlamlılık düzeyi $\mathrm{p}<0.05$ olarak kabul edildi, verilerin analizi TURCOSA (Turcosa Analytics Ltd Co, Turkey, www.turcosa.com.tr) istatistik yazılımı kullanılarak gerçekleştirildi.

\section{BULGULAR}

YBÜ'de belirtilen süre içerisinde ve kriterlerde K.pneumoniae enfeksiyonu gelişen toplam 88 hasta çalışmaya dahil edilmiştir. Hastaların yaş ortalaması $74 \pm 15$ (yaş aralığı: 
21-93) yıl olarak belirlenmiş olup \%60.2'sini kadınlar oluşturmuştur. KDKP enfeksiyonu 32 (\%36.4) hastada, karbapeneme duyarlı/hassas K.pneumoniae (KHKP) enfeksiyonu ise 56 hastada saptanmıştır. KDKP saptanan olgularda kombine disk difüzyon yöntemi ile yapılan karbapenemaz tarama testinde $\% 68.8$ oranında OXA-48, \%6.3 oranında MBL ve \%6.3 oranında KPC varlığı saptanmıştır.

Her iki grupta ortaya çıkan nozokomiyal enfeksiyonlar sırasıyla kan dolaşımı enfeksiyonu, üriner sistem enfeksiyonu ve pnömoni olarak saptanmıştır (\%40.9, \%36.4, \%18.2) (Tablo I).

Tablo II'de, K.pneumoniae enfeksiyonu gelişen hastalar arasından KDKP gelişiminde hastaların klinik özellikleri, yapılan invaziv işlemler, eşlik eden hastalıklar, enfeksiyon gelişmeden önceki son üç aylık dönemde maruz kaldıkları antibiyotikler, beslenme şekli gibi potansiyel risk faktörlerinin tek değişkenli ve çok değişkenli analiz sonuçları gösterilmiştir. Bu analizlere göre; hastalarda ameliyat dreni varlığı, enteral beslenme, enfeksiyon ortaya çıkmadan önceki son üç aylık dönem içerisinde sefalosporin, karbapenem, kolistin ve aminoglikozit gibi antibiyotiklere maruziyet KDKP ile ilişkili enfeksiyonların gelişimi ile ilişkili bulunmuştur $(p<0.10)$. Çok değişkenli lojistik regresyon analizinde KDKP gelişimi açısından iki bağımsız risk faktörü bulunmuştur. Bunlar son üç aylık dönem içerisinde kolistin $(O R=19.108 ; \% 95 G A=2.027-180.133 ; p=0.010)$ ve aminoglikozit $(O R=12.189$; \%95 $G A=1.256-118.334 ; p=0.031$ ) kullanımıdır. Kolistine maruziyet KDKP gelişme riskini 19.108 kat arttırırken, aminoglikozit maruziyetinin KDKP gelişiminde 12.189 kat risk oluşturduğu görülmüştür. Çalışma döneminde 28 günlük mortalite oranları KDKP grubunda $(23 / 32) \% 71.9$, KHKP grubunda $(21 / 56) \% 37.5$ olarak bulunmuştur $(p=0.002)$. Tablo III'te 28 günlük mortalite ile ilişkili faktörlerin tek değişkenli ve çok değişkenli analizleri özetlenmiştir. Tek değişkenli analiz sonuçlarına göre; hastalarda eşlik eden kronik obstrüktif akciğer hastalığı (KOAH) varlığı, son üç ay içinde sefalosporin ve kolistin grubu antibiyotiklerle tedavi almış olma ve KDKP varlığı 28 günlük mortalite gelişimi ile ilişkili bulunmuştur $(p<0.10)$. Çok değişkenli lojistik regresyon analizinde mortalite gelişimi açısından KDKP varlığı $(O R=5.146 ; \% 95 \mathrm{GA}=1.839-14.398 ; p=0.002)$ bağımsız risk faktörü olarak bulunmuştur. KDKP varlığının mortalite gelişme riskini 5.146 kat artırdığı saptanmıştır.

\begin{tabular}{|lccc|}
\hline \multicolumn{4}{|l}{ Tablo I. Klebsiella pneumoniae ile Gelişen Enfeksiyonların Dağılımı } \\
\hline Enfeksiyon odağı & $\operatorname{KDKP}(\mathbf{n}=\mathbf{3 2})$ & KHKP $(\mathbf{n}=56)$ & Toplam $(\mathbf{n}=\mathbf{8 8})$ \\
\hline Kan dolaşımı enfeksiyonu & $13(\% 40.6)$ & $23(\% 41)$ & $36(\% 40.9)$ \\
Üriner sistem enfeksiyonu & $12(\% 37.5)$ & $20(\% 35.7)$ & $32(\% 36.4)$ \\
Pnömoni & $6(\% 18.8)$ & $10(\% 17.9)$ & $16(\% 18.2)$ \\
Yara enfeksiyonu & - & $3(\% 5.4)$ & $3(\% 3.4)$ \\
İntraabdominal enfeksiyon & $1(\% 3.1)$ & - & $1(\% 1.1)$ \\
\hline KDKP: Karbapeneme dirençli Klebsiella pneumoniae, KHKP: Karbapeneme duyarlı/hassas Klebsiella pneumoniae. \\
\hline
\end{tabular}




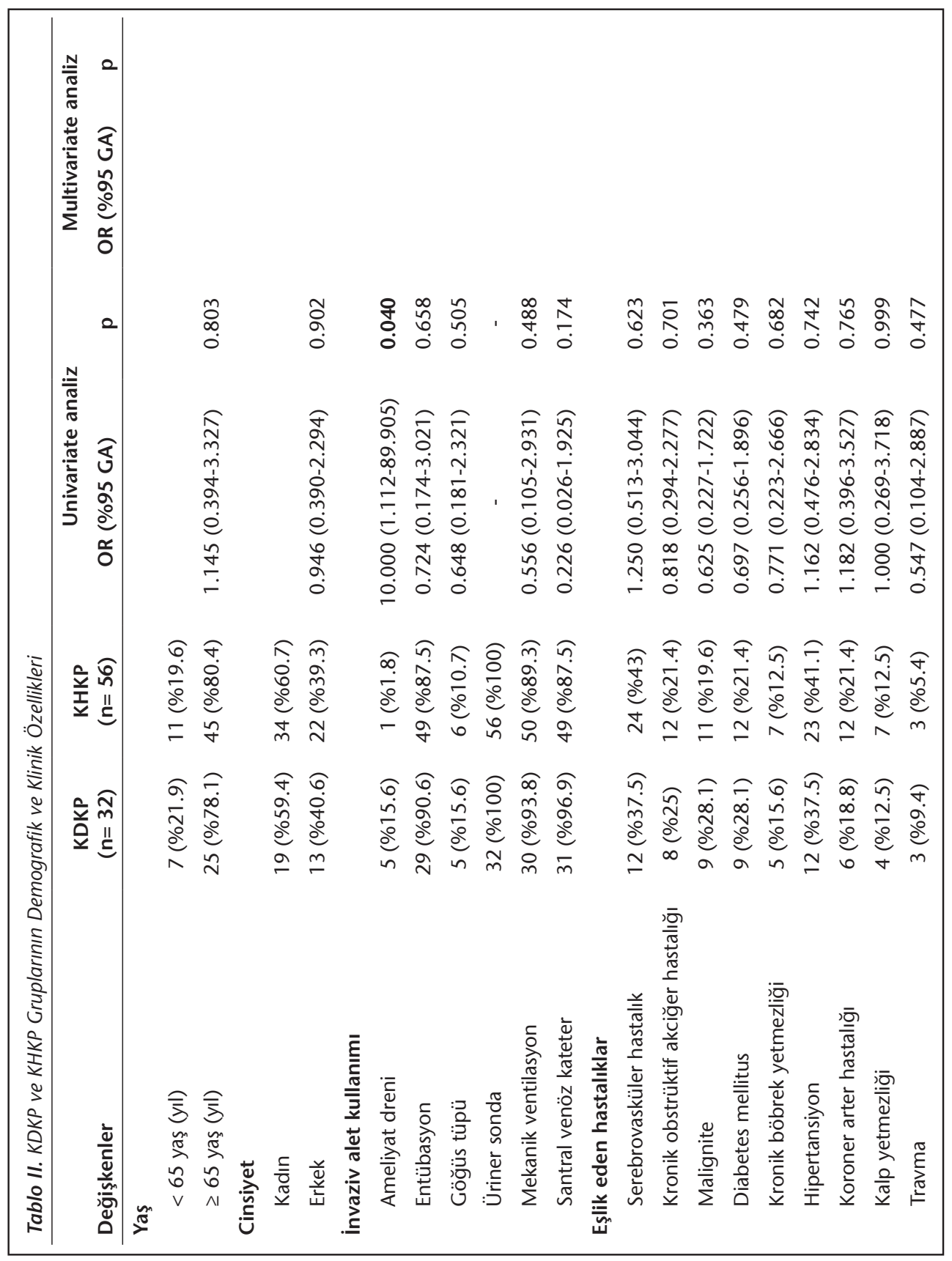




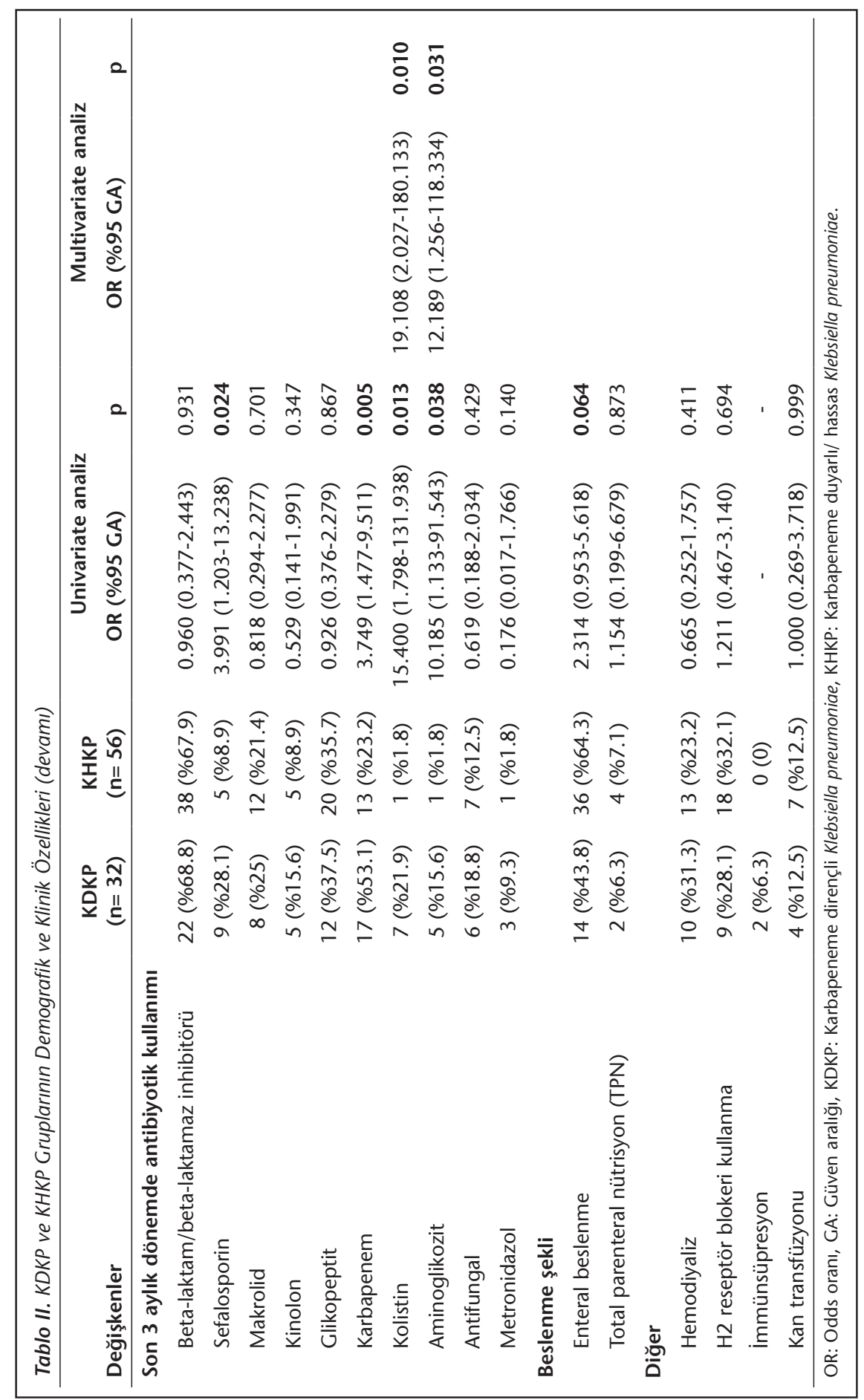




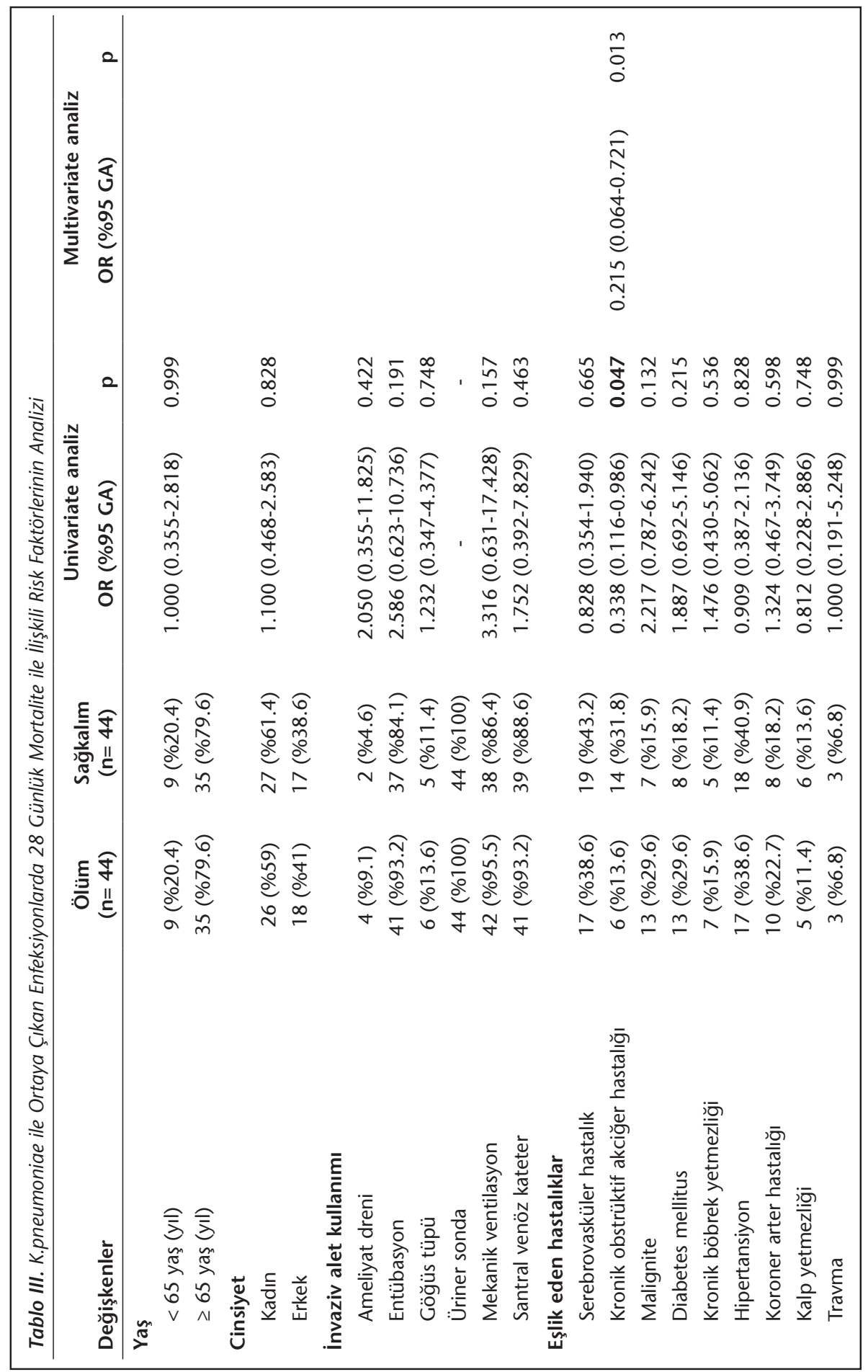




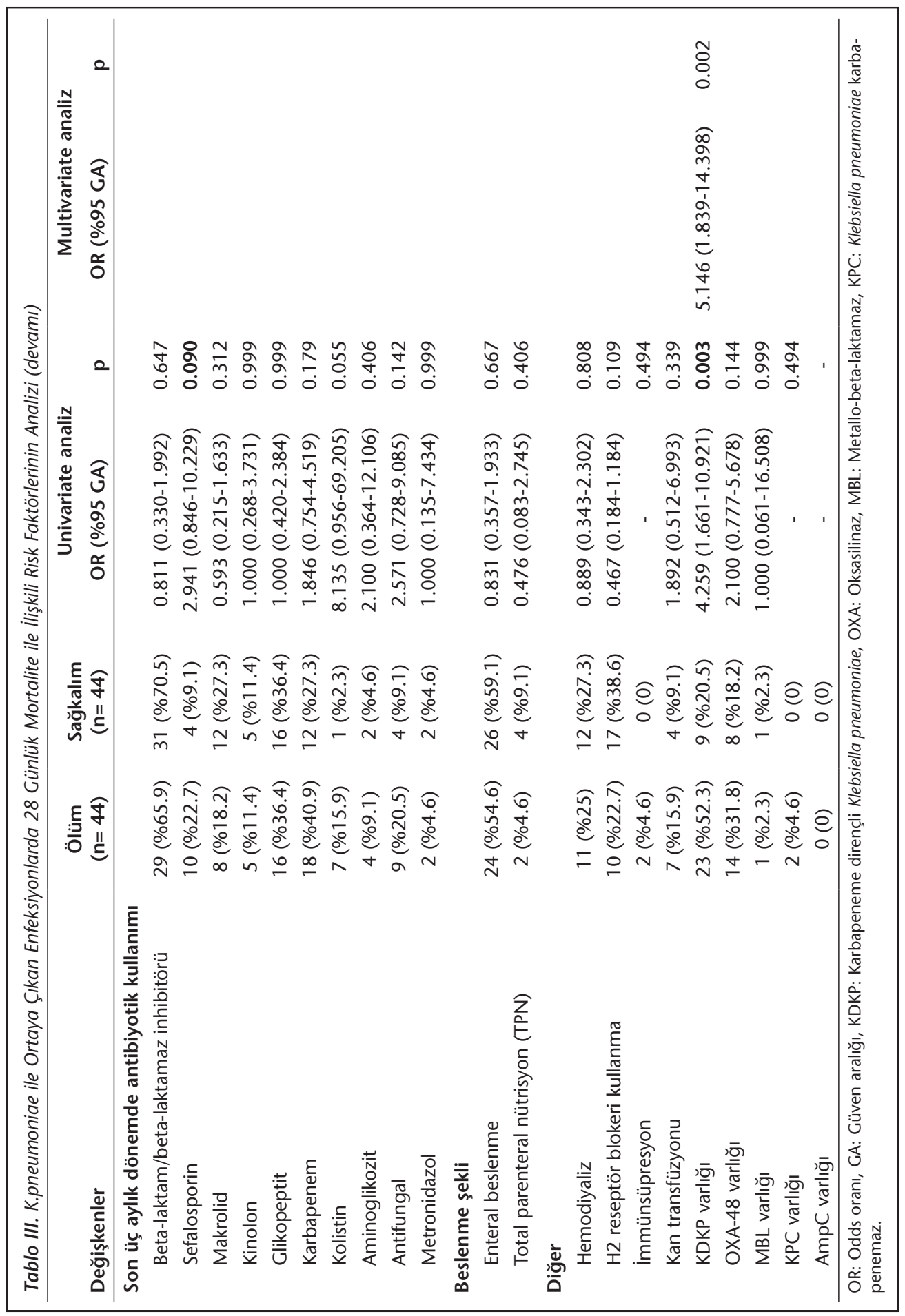




\section{TARTIŞMA}

Bu çalışmada, anestezi YBÜ'de K.pneumoniae ile ortaya çıkan enfeksiyon ataklarında, KDKP ve mortalite gelişiminde çeşitli risk faktörlerinin ilişkisi araştırılmıştır. KDKP enfeksiyonları, küresel olarak hızla yaygınlaşması, sınırlı tedavi seçenekleri ve prognoz üzerindeki olumsuz etkileri nedeniyle halk sağlığı açısından ciddi bir sorundur. Bu nedenle, erken dönemde KDKP enfeksiyonu olasılığını risk faktörleriyle belirlemek ve gerekli enfeksiyon kontrol önlemlerini almak, KDKP enfeksiyonlarının görülme sıklığını azaltmak için oldukça önemlidir ${ }^{11}$.

KDKP için tüm dünyada coğrafi bölgelere göre farklı prevalans oranları bildirilmektedir. Hindistan'da bu oran \%60 iken, İtalya'da \%36, Arjantin ve Brezilya gibi bazı Güney Amerika ülkelerinde \%15'in üzerinde karbapenem direnç oranları bildirilmiştir ${ }^{12}$. Yunanistan'da 2005 yılından 2011 yılına kadar olan süreçte KDKP izolatlarının oranının $\% 28$ 'den \%68'e çıktığı bildirilmiştir ${ }^{13}$. CAESAR 2018 yılı raporunda ülkemizden kan ve beyin omurilik sIVISı örneklerinden elde edilen K.pneumoniae izolatlarında ertapenem direnci \%43, imipenem/meropenem direnci ise \%38 olarak bildirilmiştir ${ }^{14}$. Çalışmamızda toplam 88 enfeksiyon atağında KDKP oranı \%36.4 olarak bulunmuştur. Bu çalışmanın sonucu ülkemizde elde edilen verilerle benzerlik göstermektedir.

Karbapenemazlar başlıca; New Delhi metallo-beta-laktamaz (NDM), Verona-integron mediated metallo-beta-laktamaz (VIM) ve imipenemaz (IMP) gibi MBL'ler ve serin karbapenemazlardan (KPC ve OXA tipi) oluşmaktadır ${ }^{15}$. Özellikle Uzakdoğu ülkelerinde görülen NDM içeren izolatlar günümüzde daha sıklıkla bildirilmeye başlanmıştır ${ }^{16}$. Bu durum, çocuk ve erişkin yaş gruplarında farklılık gösterebilmektedir. Zhang ve arkadaşla$\mathrm{rı}^{17}$ Çin'de pediatri yaş grubunda bakteremi ile seyreden olgularda en sık NDM-1 üreten K.pneumoniae olduğunu bildirmekteyken, başka bir çalışmada erişkin yaş grubunda baskın karbapenemaz türü KPC-2 olarak bildirilmiştir ${ }^{18}$. Yunanistan'da yapılan çok merkezli bir çalışmada KDKP izolatları arasında KPC \%66.5, NDM türü karbapenemaz \%13.7 olarak bildirilmiştir ${ }^{19}$.

Ülkemizden son yıllarda farklı karbapenemaz üreten Enterobacterales türleri ile artan bildirimler yapılmış olsa da, OXA-48 üreten türler endemiktir ${ }^{20}$. Bunu destekleyen çok merkezli bir çalışmada 2014 yılı içinde izole edilen KDKP izolatlarında en az bir karbapenemaz enzimi içeren 124 izolatın 103 (\%83.1)'ünde OXA-48 enzimi saptanmıştır ${ }^{21}$. Çalışmamızda da en sık karbapenemaz türü OXA-48 olarak belirlenmiş olup, ülke verilerimize benzer niteliktedir.

KDKP enfeksiyonu gelişiminde rol oynayan risk faktörleri üzerine yapılan çalışmalar olmasına rağmen, merkezlere göre farklılık gösteren sonuçlar bulunmaktadır. Literatür incelendiğinde; uzun süreli hastanede yatış öyküsü olması, santral venöz kateter gibi invaziv uygulama varlığı, sefalosporin, karbapenem, kinolon grubu antibiyotiklerin daha önceden kullanımı, steroid kullanımı, organ ve kök hücre transplantasyonları, yoğun bakımda uzun süre yatış ve mekanik ventilasyon gibi risk faktörleri KDKP gelişiminde risk faktörü olarak tanımlanmıştır 22,23 . 
Çalışmamızda enteral beslenme, ameliyat dreni varlığı, son üç ay içerisinde sefalosporin, karbapenem, kolistin ve aminoglikozit grubu antibiyotik kullanımı risk faktörü olarak bulunmuştur. Yapılan meta-analizde önceden antibiyotik kullanımının KDKP enfeksiyonu için bir risk faktörü olduğu, karbapenemler, aminoglikozitler, glikopeptitler, florokinolonlar ve antipsödomonal penisilinler gibi ana antibiyotiklere maruz kalan hastalarda KDKP enfeksiyonu riskinin daha yüksek olduğu bildirilmektedir ${ }^{22}$. Birçok çalışma KDKP gelişiminde ön planda karbapenem olmak üzere sefalosporin maruziyetini işaret etmektedir. Kwak ve arkadaşları ${ }^{24}$ karbapenem ve sefalosporinin önceden kullanımının KDKP gelişimi için önemli risk faktörü olduğunu işaret etmiştir. Benzer şekilde, daha önce sefalosporin kullanımının ertapenem dirençli K.pneumoniae enfeksiyonları gelişmesinde bağımsız risk faktörü olduğunu bildiren çalışmalar bildirilmiştir ${ }^{25,26}$. Erişkin yaştaki hastalara benzer şekilde Zhang ve arkadaşları ${ }^{17}$, pediatrik yaş grubu olgularında daha önce sefalosporin kullanılmasını KDKP ilişkili kan dolaşımı enfeksiyonları ile ilişkili bulmuşlardır. Çalışmamızda yapılan tek değişkenli analizde karbapenem ve sefalosporin kullanımı KDKP açısından risk faktörü bulunmasına rağmen, bağımsız bir risk faktörü olarak saptanmamıştır. Ancak kolistin ve aminoglikozit grubu antibiyotiklerin son üç ay içinde kullanılması bağımsız bir risk faktörü olarak bulunmuştur. Bulduğumuz sonucun olası nedenlerinden biri, son yıllarda YBÜ'de ortaya çıkan çok ilaca dirençli Acinetobacter spp. ilişkili salgınlarda kolistinin kullanılması olarak düşünülmüştür. Çok ilaca dirençli bu izolatların oluşturduğu enfeksiyonlar nedeniyle kombine tedavide yer alan kolistinin kullanma süresi uzayabilmektedir. Bu durumun artan KDKP ilişkili enfeksiyonlar için bir risk oluşturduğunu düşünmekteyiz. Mantrazlis ve arkadaşları ${ }^{27}$ da çalışmalarında kolistin uygulama süresinin, artmış KDKP enfeksiyonu sıklığı ile ilişkili olduğunu bildirmiştir $(p=0.025)$.

Çok ilaca dirençli gram-negatif enfeksiyonlarda aminoglikozitleri de içeren farklı kombinasyon seçenekleri de kullanılabilmektedir. Pratik uygulamalarda aminoglikozitler daha çok bir beta-laktam/beta-laktamaz inhibitörü veya karbapenem ile kombine edilmekte$\mathrm{dir}^{28}$. Antibiyotiklerin birlikte kullanımının yanı sıra yüksek dozlarda özellikle karbapenemlerle yapılan uzun süreli tedaviler intestinal mikroflorayı bozmakta, mikroorganizmalarda seleksiyona yol açmakta ve bakterilerin çok sayıda karbapenem direnç mekanizması geliştirmesine izin vermektedir ${ }^{22}$. Çalışmamızda aminoglikozitlerin KDKP gelişsiminde bağımsız bir risk faktörü olarak saptanmasının literatüre katkı sunacağını düşünmekteyiz.

Tek değişkenli ve çok değişkenli analizlerimiz, KDKP ile enfekte olanlarda bu durumun 28 günlük mortalite açısından bağımsız bir risk faktörü olduğunu açıkça göstermiştir. Çalışma döneminde 28 günlük mortalite oranları KDKP grubunda (23/32) \%71.9, KHKP grubunda (21/56) ise \%37.5 olarak bulunmuştur $(\mathrm{p}=0.002)$. Tablo III'te 28 günlük mortalite ile ilişkili faktörlerin tek değişkenli bir analizi özetlenmiştir. Tek değişkenli analiz sonuçlarına göre; hastalarda eşlik eden KOAH varlığı, son üç ay içinde sefalosporin ve kolistin grubu antibiyotikler ile tedavi almış olma ve KDKP varlığı 28 günlük mortalite gelişimi ile ilişsili bulunmuştur $(p<0.10)$. Çok değişkenli lojistik regresyon analizinde mortalite gelişimi açısından KDKP varlığı (OR= 5.146; \%95 GA= 1.839-14.398; $p=0.002]$ bağımsız risk faktörü olarak bulunmuştur. KDKP varlığının mortalite gelişme riskini 5.146 kat 
arttırdığı saptanmıştır. Xu ve arkadaşlarının yapmış olduğu bir meta-analiz çalışmasında ${ }^{29}$ KDKP ile enfekte hastaların KHKP ile karşılaştırıldığında anlamlı derecede daha yüksek mortaliteye sahip olduğu bulunmuştur. Havuzlanmış mortalite, KDKP ile enfekte hastalar arasında \%42.1 iken, KHKP ile enfekte olanlarda \%21.2 olarak bildirilmiştir. Sonuçlarımız aynı çalışmada çeşitli merkezlerin karbapenem direncine atfedilen ölüm oranları ile benzer bulunmuştur. Hoxha ve arkadaşları ${ }^{30}, K$ KKP'nin 30 günde atfedilebilir mortalitesini \%41 olarak bulmuş ve KDKP hastalarının 30 gün içinde ölme olasılığını üç kat daha fazla olarak bildirmişlerdir. Aynı çalışmada yazarlar komorbidite ve invaziv uygulamaların bağımsız bir etki göstermediğini, daha çok hastalık şiddet skoruna etki ettiğini bildirmişlerdir. Bu bulguların aksine Tian ve arkadaşları ${ }^{31}$ tarafından karbapenem direncinin daha önce bildirildiği gibi bağımsız bir mortalite belirleyicisi olmadığı belirtilmiştir.

Çalışmamızda invaziv uygulamaların bağımsız bir etki göstermediği görülmüştür. Komorbiditeler arasında yer alan $\mathrm{KOAH}$ ise, 28 günlük mortalite gelişiminde ilginç şekilde düşük bir risk faktörü olarak bulunmuştur $(\mathrm{OR}=0.215 ; \% 95 \mathrm{GA}=0.064-0.721 ; p=0.013)$. Bu durum tarafımızca açıklanamamıştır.

Çalışmamızın sınırlıı̆̆ı verilerimizin tek bir merkeze ait olmasıdır. Dolayısıyla bu konu ile ilgili ülkemiz verilerini yansıtması adına çok merkezli, ileriye dönük çalışmalara ihtiyaç vardır.

Sonuç olarak, KDKP'nin neden olduğu enfeksiyonlarda, kolistin ve aminoglikozit grubu antibiyotiklerin son üç ay içerisinde kullanımı ile güçlü bir ilişki bulunmuştur. Ayrıca, KDKP varlığı mortalite için bağımsız bir risk faktörüdür. Çalışmamız akılcı antibiyotik kullanımından sapmaların ve sonrasında gelişen karbapenem direncinin, hastalar açısından en istenmeyen sonuç olan mortalite için bağımsız bir risk faktörü olduğunu göstermesi açısından somut veriler içermektedir. Bu çalışma, YBÜ'de antibiyotik kullanımı için uygun kurumsal politikaların hazırlanması ve bu enfeksiyonların önlenmesi için etkili stratejilerin geliştirilmesine katkıda bulunabilir.

\section{ETIK KURUL ONAYI}

Bu çalışma, Cumhuriyet Üniversitesi Girişimsel Olmayan Klinik Araştırmalar Etik Kurulu onayı ile gerçekleştirildi (Tarih: 11.09.2019 ve Karar no: 2019-09/12).

\section{ÇIKAR ÇATIŞMASI}

Yazarlar bu makale ile ilgili herhangi bir çıkar çatışması bildirmemişlerdir.

\section{KAYNAKLAR}

1. Koçak CÖ, Hazırolan G. Karbapenem dirençli Klebsiella pneumoniae klinik izolatlarında kolistin direnci. Türk Mikrobiyoloji Cem Derg 2019; 49(1): 17-23.

2. Temiz H, Özbek E, Vural DG, Özekinci T. Klebsiella izolatlarının antimikrobiyal direnç oranlarının değerlendirilmesi. Türk Mikrobiyoloji Cem Derg 2015; 45(2): 68-74.

3. Bengoechea JA, Sa Pessoa J. Klebsiella pneumoniae infection biology: living to counteract host defences. FEMS Microbiol Rev 2019; 43(2): 123-44. 
Yoğun Bakım Ünitesinde Gelișen Klebsiella pneumoniae Enfeksiyonları:

Karbapenem Direnci ve Hasta Mortalitesi ile İlgili Risk Faktörleri

4. Özakın C. Klebsiella türleri, pp: 1870-2. Topcu AW, Söyletir G, Doğanay M (editörler), Enfeksiyon Hastalıkları ve Mikrobiyolojisi. 2017, 4. Baskı, Nobel Tıp Kitabevleri, İstanbul.

5. Kaye KS, Pogue JM. Infections caused by resistant gram negative bacteria: epidemiology and management. Pharmacotherapy 2015; 35(10): 949-62.

6. Sheu CC, Chang YT, Lin SY, Chen YH, Hsueh PR. Infections caused by carbapenem-resistant Enterobacteriaceae: an update on therapeutic options. Front Microbiol 2019; 10: 80.

7. Candevir Ulu A, Kurtaran B, Inal AS, Kömür S, Kibar F, Yapıcı Çiçekdemir H, et al. Risk factors of carbapenemresistant Klebsiella pneumoniae infection: a serious threat in ICUs. Med Sci Monit 2015; 21: 219-24.

8. Pan H, Lou Y, Zeng L, Wang L, Zhang J, Yu W, et al. Infections caused by carbapenemase-producing Klebsiella pneumoniae: microbiological characteristics and risk factors. Microb Drug Resist 2019; 25(2): 287-96.

9. Horan TC, Andrus M, Dudeck MA. CDC/NHSN surveillance definition of health-care-associated infection and criteria for specific types of infections in the acute care setting. Am J Infect Control 2008; 36(5): 309-32.

10. European Committee on Antimicrobial Susceptibility Testing. EUCAST clinical MIC breakpoints. http://www. eucast.org

11. Wang Z, Qin RR, Huang L, Sun LY. Risk factors for carbapenem-resistant Klebsiella pneumoniae infection and mortality of Klebsiella pneumoniae infection. Chin Med J (Engl) 2018; 131(1): 56-62.

12. Theuretzbacher U. Global antimicrobial resistance in gram-negative pathogens and clinical need. Curr Opin Microbiol 2017; 39: 106-12.

13. European Centre for Disease Prevention and Control (ECDC). 2012. Antimicrobial resistance surveillance in Europe 2011. Annual Report of the European Antimicrobial Resistance Surveillance Network (EARS-Net).

14. http://www.euro.who.int/en/health-topics/disease-prevention/antimicrobial resistance/publications/2018/ central-asian-and-eastern-european-surveillance-of-antimicrobial-resistance-annual-report-2018

15. Bush K. Carbapenemases: Partners in crime. J Glob Antimicrob Resist 2013;1(1): 7-16.

16. Hoang CQ, Nguyen HD, Vu HQ, Nguyen AT, Pham BT, Tran TL, et al. Emergence of New Delhi metallobeta-lactamase (NDM) and Klebsiella pneumoniae carbapenemase (KPC) production by Escherichia coli and Klebsiella pneumoniae in southern Vietnam and appropriate methods of detection: A cross-sectional study. Biomed Res Int 2019; 2019: 9757625.

17. Zhang Y, Guo LY, Song WQ, Wang Y, Dong F, Liu G. Risk factors for carbapenem-resistant K.pneumoniae bloodstream infection and predictors of mortality in Chinese paediatric patients. BMC Infect Dis 2018; 18(1): 248.

18. Zheng B, Dai Y, Liu Y, Shi W, Dai E, Han Y, et al. Molecular epidemiology and risk factors of carbapenemresistant Klebsiella pneumoniae infections in eastern China. Front Microbiol 2017; 8: 1061.

19. Galani I, Karaiskos I, Karantani I, Papoutsaki V, Maraki S, Papaioannou V, et al. Epidemiology and resistance phenotypes of carbapenemase-producing Klebsiella pneumoniae in Greece, 2014-2016. Euro Surveill 2018; 23(31).

20. Albiger B, Glasner C, Struelens MJ, Grundmann H, Monnet DL; European Survey of Carbapenemaseproducing Enterobacteriaceae (EuSCAPE) working group. Carbapenemase-producing Enterobacteriaceae in Europe: assessment by national experts from 38 countries, May 2015. Euro Surveill 2015; 20(45).

21. Çakar A, Akyön Y, Gür D, Karatuna O, Öğünç D, Özhak Baysan B, et al. Investigation of carbapenemases in carbapenem-resistant Escherichia coli and Klebsiella pneumoniae strains isolated in 2014 in Turkey. Mikrobiyol Bul 2016; 50(1): 21-33

22. Liu P, Li X, Luo M, Xu X, Su K, Chen S, et al. Risk factors for carbapenem-resistant Klebsiella pneumoniae infection: a meta-analysis. Microb Drug Resist 2018; 24(2): 190-8.

23. Özger HS, Karaşahin Ö, Telli G, Gaygısız G, Civil F, Dizbay M. Nozokomiyal Klebsiella türleri arasında karbapenem direnç sıklığı ve fenotipik yöntemlerle direncin değerlendirilmesi. FLORA 2012; 17(3): 103-10.

24. Kwak YG, Choi SH, Choo EJ, Chung JW, Jeong JY, Kim NJ, et al. Risk factors for the acquisition of carbapenemresistant Klebsiella pneumoniae among hospitalized patients. Microb Drug Resist 2005; 11(2): 165-9. 
25. Orsi GB, Garcia-Fernandez A, Giordano A, Venditti C, Bencardino A, Gianfreda R, et al. Risk factors and clinical significance of ertapenem resistant Klebsiella pneumoniae in hospitalized patients. J Hosp Infect 2011; 78(1): 54-8.

26. Liu SW, Chang HJ, Chia JH, Kuo AJ, Wu TL, Lee MH. Outcomes and characteristics of ertapenemnonsusceptible Klebsiella pneumoniae bacteremia at a university hospital in northern Taiwan: a matched case-control study. J Microbiol Immunol Infect 2012; 45(2): 113-9.

27. Mantzarlis K, Makris D, Manoulakas E, Karvouniaris M, Zakynthinos E. Risk factors for the first episode of Klebsiella pneumoniae resistant to carbapenems infection in critically ill patients: a prospective study. Biomed Res Int 2013; 2013: 850547.

28. Bassetti M, Peghin M, Vena A, Giacobbe DR. Treatment of infections due to MDR gram-negative bacteria. Front Med (Lausanne) 2019; 6: 74.

29. Xu L, Sun X, Ma X. Systematic review and meta-analysis of mortality of patients infected with carbapenemresistant Klebsiella pneumoniae. Ann Clin Microbiol Antimicrob 2017; 16(1): 18.

30. Hoxha A, Kärki T, Giambi C, Montano C, Sisto A, Bella A, et al. Attributable mortality of carbapenemresistant Klebsiella pneumoniae infections in a prospective matched cohort study in Italy, 2012-2013. J Hosp Infect 2016; 92(1): 61-6.

31. Tian L, Tan R, Chen Y, Sun J, Liu J, Qu H, et al. Epidemiology of Klebsiella pneumoniae bloodstream infections in a teaching hospital: factors related to the carbapenem resistance and patient mortality. Antimicrob Resist Infect Control 2016; 5: 48. 